\title{
HELICOBACTER PYLORI INFECTION AND BRAIN DYSFUNCTION
}

Helicobacter pylori infection was identified in 5 children with severe neurologic impairment who underwent upper gi endoscopy at the Alfred I duPont Institute, Wilmington, De, and Jefferson Medical College, Philadelphia. Subsequently, patients with severe neurologic impairments, such as cerebral palsy and head trauma, who had endoscopies because of gastrointestinal symptoms were examined for $H$. pylori infection in gastric antral mucosa biopsies. Of 61 examined, 7 (11\%) were positive for infection and had gastritis. Institutionalized patients were at much greater risk of infection than those seen as outpatients (75\% cf 7\%). Resolution of gi symptoms (emesis, guiacpositive stools, refusal to eat, and irritability during feedings) was complete in 6 of the 12 infected patients and partial in 4 after antibiotic treatment. (Proujansky R et al. Symptomatic Helicobacter pylori infection in young patients with severe neurologic impairment. I Pediatr Nov 1994;125:750-752). (Reprints: Roy Proujansky MD, Alfred I duPont Institute, 1600 Rockland Rd, Wilmington, DE 19899).

COMMENT. All neurologically impaired, and especially institutionalized, children with persistent gastrointestinal symptoms should be examined and treated when positive for $H$. pylori infection.

A possible $H$. pylori infection should be considered in children with epilepsy who develop gastritis and feeding difficulties after longterm treatment with valproic acid, divalproex sodium, and other antiepileptic drugs. (see Progress in Pediatric Neurology I, PNB Publishers, 1991). Gastritis and gastric ulceration attributed to the antiepileptic drugs may be due primarily to infection in the gastric mucosa.

\section{NEOPLASTIC DISORDERS}

\section{OUTCOME OF OPSOCLONUS WITH NEUROBLASTOMA}

The neurologic and developmental outcomes in 10 children with opsoclonus-myoclonus ("dancing eyes syndrome") and neuroblastoma were reviewed by examination of records at Northwestern University Medical School and Children's Memorial Hospital, and the University of Illinois Hospital, Chicago. Ages ranged from 8 months to 30 months. Opsoclonus and ataxia had been present from 6 days to 1 year before diagnosis of neuroblastoma. All had localized disease and 50\% had extraabdominal tumors. All are alive and without recurrence of tumor 8 months to 111 months after resection. All had opsoclonus-myoclonus or ataxia for at least 5 months after surgery, but eventually responded to ACTH therapy. Two were symptom-free 12 months after surgery, and 3 remitted after 36 months. Nine relapsed and had chronic deficits, including cognitive and motor delays, reading and language deficits, and behavioral abnormalities. Factors precipitating recurrences of opsoclonus-myoclonus or ataxia included discontinuance or reduction of ACTH, febrile illness, and immunizations. (Koh PS, Raffensperger JG et al. Long-term outcome in children with opsoclonus-myoclonus and ataxia and coincident neuroblastoma. I Pediatr Nov 1994;125:712-716). (Reprints: John G Raffensperger MD, Pediatric Surgery, Children's Memorial Hospital, 2300 Children's Plaza, Chicago, IL 60614). 
COMMENT. All children with neuroblastoma and opsoclonus-myoclonus and ataxia had an excellent surgical outcome and their eye movement disorder eventually responded to ACTH. The majority have long-term learning and behavioral problems, requiring special remedial education and behavioral intervention. Immunizations should be delayed or withheld when possible to avoid relapse of opsoclonus and ataxia.

\section{CRANIOPHARYNGIOMA: RECURRENCE FACTORS}

Factors predictive of recurrence and functional outcome were determined in a retrospective clinicopathological analysis of 56 patients (26 children and 30 adults) operated on for craniopharyngioma since 1981 at New York University Medical Center. Children underwent gross total resection (GTR) of tumor more frequently than adults (77\% cf $27 \%$ ). Tumors were almost all adamantinomatous in children, whereas in adults, two thirds were adamantinomatous and one third were squamous papillary. Brain invasion was most frequent with the adamantinomatous craniopharyngiomas; invasion had occurred in $46 \%$ of the children compared with $17 \%$ of adults. Subtotal resection was associated with a higher rate of recurrence compared with total resection. Brain invasion had no effect on recurrence rate in totally resected cases. Functional, visual, and endocrine outcomes were not sacrificed by total resection of tumor. (Weiner $\mathrm{HL}$ et al. Craniopharyngiomas: a clinicopathological analysis of factors predictive of recurrence and functional outcome. Neurosurgery December 1994;35:1001-1011). (Reprints: Howard L Weiner MD, Dept of Neurosurgery, New York University Medical Center, 550 First Ave, New York, NY 10016).

COMMENT. The single most important factor predictive of craniopharyngioma recurrence is the extent of surgical resection. Total compared to subtotal resection has a significantly lower recurrence rate without affecting functional outcome. Brain invasion does not predict higher recurrence provided the tumor is totally resected.

Estogen Receptor Gene Expression. Craniopharyngiomas are histologically benign neoplasms of the sellar region that frequently show local invasion of brain tissue. In a collaborative study at the University of Toronto, Canada, the Mayo Clinic, and the University of Virginia, Charlottesville, 23 surgically removed craniopharyngiomas uniformally expressed the estrogen receptor gene. A possible hormonal component to the genesis and progression of craniopharyngiomas and investigation of hormonal therapy are suggested.

\section{SPEECH AND LANGUAGE DISORDERS}

\section{CEREBELLAR MUTISM}

Of a series of 15 children operated for cerebellar tumor at University Hospital Rotterdam-Dijkzigt, The Netherlands, 5 developed "cerebellar mutism" and subsequent dysarthria after surgery, and 2 had mild speech problems. Of 8 without speech problems, 7 had astrocytomas, with involvement of a cerebellar hemisphere. Of the 5 with mutism, 4 had medulloblastomas, and all had tumors that lined the fourth ventricle. Mutism was delayed for 1 to 2 days after surgery. Alternating movements of the tongue were impaired but no paresis of bulbar muscles was evident in mute patients. The duration of mutism 